\title{
O INTÉRPRETE DIANTE DO TEXTO: APROXIMAÇÕES ENTRE A LEITURA DA TORÁ, DO CORÃO E DA CONSTITUIÇÃO
}

\author{
THE INTERPRETER IN FRONT OF THE TEXT: \\ APPROXIMATIONS BETWEEN THE READING OF THE TORAH, OF THE \\ QUR'AN AND OF THE CONSTITUTION
}

\author{
Eduardo Borges Araújo* \\ Juliano Zaiden Benvindo**
}

\begin{abstract}
RESUMO: a doutrina constitucional brasileira do final do século XX e início do século XXI revelou um fascínio pela principiologia e ponderação. Atribui-se o enfraquecimento do caráter normativo da Constituição ao discurso jurídico-axiológico das Cortes Constitucionais, cujos ministros praticariam uma teologia constitucional ao deduzirem diretamente do texto todos os valores e comportamentos corretos. Porém, assim como no Direito, verifica-se na teologia uma preocupação constante com os métodos de interpretação dos textos sagrados, de maneira que resulta impossível reduzir sua rica experiência hermenêutica à jurisprudência de valores. Para ilustrar o argumento, será explorado o debate sobre a leitura da Torá e do Corão, com o fim de evidenciar os distintos métodos interpretativos possíveis. Em segundo lugar, a análise recairá sobre a história constitucional americana, sobretudo no que diz respeito à relação entre interpretação e emenda e ao papel hermenêutico da Suprema Corte, para que, na conclusão, possam ser traçados paralelos entre a interpretação da Torá, do Corão e da Constituição.
\end{abstract}

PALAVRAS-CHAVE: Corão. Emenda constitucional. Hermenêutica constitucional. Torá.

ABSTRACT: The Brazilian constitutional literature of the late twentieth century and early twenty-first century revealed a fascination for principles and for weighting. The weakening of the normative character of the Constitution was attributed to the legal-axiological discourse of Constitutional Courts, whose justices would practice a constitutional theology to deduct directly from the text all the correct values and behaviors. However, as it is in Law, there is a constant concern in theology about the methods of interpretation of sacred texts that makes impossible to reduce its rich hermeneutical experience to a jurisprudence of values. To illustrate the argument, we will explore the debate over the reading of the Torah and of the Koran, in order to show the different possible interpretive methods. Secondly, we will focus on American constitutional history, especially in regard to the relationship between interpretation and amendment and to the hermeneutical role of the Supreme Court, so that, in

\footnotetext{
* Bacharel em Ciências Jurídicas pela Universidade Federal do Paraná (UFPR). Mestrando em Direito, Estado e Constituição pela Universidade de Brasília (UnB). Pesquisador do Grupo de Pesquisa Constitucionalismo e Democracia: Filosofia e Dogmática Constitucional Contemporâneas (PPGD/UFPR). Bolsista da Coordenação de Aperfeiçoamento de Pessoal de Nível Superior (CAPES).

** Professor de Direito Público da Universidade de Brasília (UnB). Atualmente, realiza Estágio Pós-Doutoral na Universidade de Bremen (Alemanha). Doutor em Direito pela Universidade Humboldt de Berlim (Alemanha) e pela Universidade de Brasília (UnB).
}

Revista da Faculdade de Direito - UFPR, Curitiba, vol. 59, n. 2, p. 47-73, 2014. 
the conclusion, we can draw parallels between the interpretation of the Torah, of the Qur'an and of the Constitution.

KEYWORDS: Constitutional amendment. Constitutional interpretation. Qur'an. Torah.

\section{INTRODUÇÃO}

“Após a escuridão de um longo período, a luz se acende! Veio mostrar a clareza, apontar os caminhos, evitar os choques, permitir o início de um novo momento em que podemos olhar o que outrora estava escondido nas sombras de um quarto fechado" (SCHIER, 2005, p. 4). Em 1985, com o fim do regime militar e a discussão sobre transição democrática, a ciência e a teoria políticas brasileiras despertaram para o debate sobre a constitucionalização do direito. Assim como fizera com a realidade política do Brasil, a democracia supostamente viera para transformar nossa doutrina constitucional: "Precisou o neoconstitucionalismo trazer a luz e as águas reparadoras ao mundo do Direito" (SCHIER, 2005, p. 5). Por mais que pareça duvidoso que tais transformações possam ser interpretadas de forma tão causal, é certo que o constitucionalismo brasileiro, ao final do século XX e início do século XXI, demonstrou um fascínio pela principiologia e ponderação que levou à trivialização da relação entre princípios e regras (NEVES, 2013).

Revela-se impossível reduzir o neoconstitucionalismo a uma definição clara e coesa, na medida em que sua relevância teórica está mais em servir como guarda-chuva a distintas concepções sobre o fenômeno jurídico, cujas particularidades, ainda que possam ser traçadas a denominadores em comum, comprometem a formulação de um conceito de maior precisão (SARMENTO, 2009). Mesmo diante de controvérsias em torno de sua conceituação e suas características, a doutrina não diverge quanto à identificação da presente conjuntura da teoria constitucional como neoconstitucionalista, atribuindo-lhe como traços característicos o distanciamento do positivismo jurídico e a vinculação entre direito e moral na interpretação da constituição dos Estados modernos (DIMOULIS, 2008). Foi tamanha fluidez conceitual que permitiu o enquadramento de jusfilósofos dos mais distintos matizes teóricos na categoria de pensadores neoconstitucionalistas, a exemplo de Robert Alexy e Ralf Dreier na Alemanha, Gustavo Zagrebelsky e Luigi Ferrajoli na Itália, Manuel Atienza na Espanha, Ronald Dworkin nos Estados Unidos, Carlos Santiago Nino na Argentina e Lênio Streck no Brasil.

Seria mérito deste movimento as "três grandes transformações [que] subverteram o conhecimento convencional relativamente à aplicação do direito constitucional" (BARROSO, 2007, p. 5): a atribuição de força normativa à Constituição, o fortalecimento e a expansão da 
jurisdição constitucional e a interpretação da Constituição a partir de elementos normativos de maior abstração e técnicas de ponderação entre direitos e interesses. Embora uma investigação detalhada revele que nenhuma destas "transformações" constitua propriamente uma novidade, o que é decisivo nesta nova conjuntura teórica é o entendimento sobre a relação entre direito e moral na interpretação da Constituição, que é contemporaneamente protagonizada por Cortes Constitucionais a partir de referências corriqueiras a princípios e valores constitucionais e a técnicas de ponderação (DIMOULIS, 2008).

A amplitude da atuação das cortes constitucionais consolida-se e, paradoxalmente, o caráter normativo da Constituição, cujo dever de tutela lhe é próprio, é relativizado em prol de uma atuação casuística do Poder Judiciário, cada vez mais presente no plano político ao valerse de um discurso político-axiológico reforçado pela aura da última palavra e da supremacia (WHITTINGTON, 2007; HIRSCHL, 2004). Desta forma, impõe-se uma lógica decisória que externaliza uma forma de ativismo judicial pouco atento aos limites da racionalidade jurídica, cuja consequência é uma nítida reorganização institucional que suscita importantes discussões no âmbito da separação dos poderes e das perspectivas de justiça (BENVINDO, 2010). Além da ampliação das competências objetivas do Poder Judiciário, facilitada pela consolidação do controle judicial sobre o legislador e o aumento da disposição para litigância, a "excepcional personalidade de jurista", considerada pressuposto para tomada de decisões racionais e justas, centralizou na Justiça a consciência social, eliminando o processo de construção política dos consensos e deslocando ao Judiciário a decisão sobre valores sociais (MAUS, 2000, p. 186).

Nesta fuga da complexidade, a apropriação pela Corte Constitucional da persecução dos interesses sociais, dos processos de formação da vontade política e dos discursos morais é conquistada mediante uma radical transformação no conceito de Constituição, que não mais encerraria as liberdades e as garantias fundamentais, mas sim "um texto fundamental, a partir do qual, a exemplo da Bíblia e do Corão, os sábios deduziriam diretamente todos os valores e comportamentos corretos" (MAUS, 2000, p. 192). Denuncia-se, dessa maneira, a teologia constitucional que é atualmente praticada pelas Cortes na interpretação da Constituição.

Mas, por trás dessa referência, reside mais do que uma simplificação da experiência teológica. Ao reduzir os métodos hermenêuticos presentes na teologia a um conceito genérico e abstrato, Ingeborg Maus incorre em um equívoco e esclarecê-lo será o primeiro objetivo do presente artigo. Assim como a hermenêutica constitucional, cujo objeto de interpretação é o texto constitucional, a teologia testemunha há séculos a disputa entre distintas correntes sobre qual o mais adequado método de interpretação dos respectivos textos sagrados, seja pautado pela literalidade das escrituras, pelo interesse da coletividade ou pelos princípios subjacentes 
ao texto - de maneira muito semelhante às opções hermenêuticas próprias do direito. Ilustrar essas semelhanças constitui o segundo objetivo do trabalho, cuja tese a ser demonstrada ao final é a de que a menção à teologia constitucional revela um injustificado preconceito, que ignora ou diminui as particularidades da teologia, e um visível desconhecimento dos paralelos existentes entre as experiências na teologia e no direito. Será, portanto, de grande valia explorar as discussões em torno da interpretação adequada da Torá e do Corão, o que será feito nos dois primeiros tópicos do artigo. Analisadas essas experiências, de forma a evidenciar o quão plurais são os métodos de interpretação, passa-se à discussão travada em torno da leitura do texto sagrado dos americanos, a Constituição, de modo a possibilitar que, nas considerações finais, sejam traçadas as aproximações entre as experiências na teologia e no direito.

\section{O INTÉRPRETE DA TORÁ}

A primeira referência da Bíblia aos dez mandamentos encontra-se no capítulo 24 do Êxodo, na passagem de seu verso 12: “O Senhor disse a Moisés: 'Sobe para mim no monte. Ficarás ali para que eu te dê as tábuas de pedra, a lei e as ordenações que escrevi para sua instrução"”. Em seguida, narra o verso 13 que "Moisés levantou-se com Josué, seu auxiliar, e subiu o monte de Deus", no que uma densa nuvem envolveu o Sinai e ali ficou por seis dias e seis noites. Com a chegada do sétimo dia, Deus convocou Moisés a adentrar a nuvem, onde permaneceu por quarenta dias e noites. Aflitos com a demora, os libertos do Egito terminaram por inventar e louvar seu próprio deus, a quem honraram com estátuas, sacrifícios e banquetes. Ao retornar do Monte Sinai com o decálogo, Moisés deparou-se com o acampamento e "viu [a estátua d]o bezerro e as danças. Sua cólera se inflamou, arrojou de suas mãos as tábuas e quebrou-as ao pé da montanha".

Como ilustrado pelos capítulos 32 e 33 do Êxodo, a reação de Moisés foi convocar todos os membros de sua tribo a assassinar os demais libertos com o fim de obterem o perdão divino. No que Deus voltou a se revelar, assim instruiu a Moises: "Talha duas tábuas de pedra semelhantes às primeiras: escreverei nelas as palavras que se encontravam nas primeiras tábuas que quebraste". Na volta do Monte Sinai, conta o verso 10 do capítulo 9 do Livro do Deuteronômio, foram entregues a Moisés as duas tábuas em que Deus voltou a gravar as dez palavras que anteriormente insculpira nas tábuas quebradas por Moisés. Os ensinamentos e os mandamentos ali registrados por Deus compreendem a norma fundamental e o valor supremo do direito judaico. 
As revelações escritas nas tábuas entregues por Deus a Moisés passaram a constituir a Torá, à qual foram incorporados os ensinamentos tardios sobre o Judaísmo que permitiriam sua aplicabilidade. Ao ampliar seu conteúdo para além dos cinco livros de Moisés ${ }^{1}$, a Torá diferenciou-se em suas versões escrita e oral. Foi justamente para auxiliar a interpretação da Torá escrita que Deus igualmente revelou a Torá oral, cuja denominação justifica-se pela sua origem nas leis e nas lições oralmente transmitidas a Moisés e posteriormente transcritas pelos sábios judeus. Ao lado do registro textual, um extenso corpo de instruções orais revestiu-se da autoridade divina, na medida em que era fruto igual de sua revelação (ZOHAR, 1995). Nele, Deus especificou as minúcias de suas leis, ainda que deixasse clara "a necessidade de interpretação humana do texto no que diz respeito a estes detalhes" (LEVINE, 1997, p. 445)². Ainda, ensinou a Moisés os métodos que deveriam ser utilizados na interpretação da Torá entre eles, um modelo de interpretação literal do texto (LEVINE, 1997, p. 445).

No início, os ensinamentos da Torá oral eram transmitidos verbalmente de geração para geração, através de um elaborado sistema de ensino. Porém, por consequência de exílios e perseguições sofridas, a Torá oral foi reduzida a um documento escrito. Assim, sob a forma de compilação escrita autorizada da Torá oral, surge o Talmude. Seu livro primeiro, a Mishnah, é produto das reflexões conduzidas por mais de cinco gerações pelo grupo de sábios rabínicos Tannaim, entre os anos 70 e 200. Ao término das discussões, ficou sob a responsabilidade do Rabino Judá HaNasi redigir as principais conclusões tiradas sobre leis, tradições e sabedorias convencionais. O conteúdo da Mishnah encontra-se organizado de acordo com o assunto que é tratado em cada uma das suas seis ordens (STRACK; STEMBERGER, 1996, p. 110-118). A primeira, chamada Zerain, dispõe sobre reza, benção, dízima e agricultura. A segunda, Moed, disciplina os rituais do Sabá e as festas judaicas. Casamento, divórcio, juramento e nazireu ${ }^{3}$ são tratados pela Nashim, a terceira das ordens. Em seguida, a Mishnah cuida de matérias de direito civil e penal, bem como do sistema de administração da justiça, na ordem Nezikin. São tratadas pela sexta e sétima ordens, Kodashim e Tehorot, questões religiosas, como rituais de sacrifício e regras de alimentação.

\footnotetext{
${ }^{1}$ A Torá escrita, Torah Shebichtav, é composta pelos cinco primeiros livros da Tanakah - da "Bíblia judaica". Cada livro recebe o nome a partir de sua primeira frase: Bereshit advém de "No começo..."; Shemot, de "Estes são os nomes..."; Vayikra, de "E o Senhor chamou a Moisés..."; Bamidbar, de "No deserto do Sinai..." e Devarim, de "Estas são as palavras...".

${ }^{2}$ Todas as citações de obras referenciadas em inglês nesta obra possuem tradução livre do autor.

${ }^{3} \mathrm{O}$ nazireu remete ao compromisso tomado por alguém que decide consagrar-se totalmente a Deus, abstendo-se dos "prazeres mundanos", como sexo ou álcool. O traço típico dos nazireus era o cabelo comprido, que era cortado apenas com o fim do compromisso e oferecido em sacrifício.
}

Revista da Faculdade de Direito - UFPR, Curitiba, vol. 59, n. 2, p. 47-73, 2014. 
A segunda parte do Talmude, a Gemara, abarca leituras e estudos sobre as tradições consolidadas pelas reflexões dos Tannaim e anotações de Judá NaHasi. Assim, o aprendizado dos costumes realizado pelos sábios Amorain foi assimilado "como 'complemento' da Torá escrita ou como complemento do estudo em si” (STRACK; STEMBERGER, 1996, p. 105). Curiosamente, dois grupos de estudiosos debruçaram-se sobre esta tradição, em um processo que culminou na produção de duas Gemaras e, consequentemente, de dois Talmudes. Logo, há o Talmude de Jerusalém e o Talmude da Babilônia, que compartilham da mesma Mishnah, mas não da mesma Gemara.

Em termos de estrutura, o conteúdo legal da Torá pode ser distinguido entre mitzvot e princípios (LEVINE, 1997, p. 451). A primeira categoria, relacionada sobretudo a aspectos técnicos do judaísmo, impõe deveres positivos ou negativos a determinadas atividades. Ainda que dúvidas surjam quanto à incidência dos mitzvot, o conteúdo do mandamento é geralmente de fácil identificação. Caso as informações necessárias ao caso concreto não fossem fornecidas pelo direito escrito, sua solução seria encontrada junto ao direito oral. Como resultado, vê-se que "as autoridades que interpretam a Torá têm um papel limitado, bem como uma limitada discricionariedade na definição destas atividades” (LEVINE, 1997, p. 461). Na hipótese de aplicação da mitzva a novas situações ou de interpretação de termos não pormenorizados pelo direito oral, as regras que são ou textualmente previstas ou logicamente concebidas delineiam algumas diretrizes sobre permissões e proibições. Inexiste a faculdade de, a partir da vontade divina por trás da mitzva em questão, deixar de aplicá-la. Em regra, a exegese não pode restringir sua incidência. Quando vislumbradas novas circunstâncias, as autoridades rabínicas deverão decidir sobre aplicar ou não a mitzva para além de seu texto (LEVINE, 1997, p. 460).

Além do conteúdo, que compreende questões civis, os princípios diferenciam-se dos mitzvot em relação à sua estrutura. Não fixando de antemão o que deve ou não ser praticado, os princípios constituem standards jurídicos que prescrevem à sociedade um modelo ideal de funcionamento (LEVINE, 1997, p. 462). O fundamento da maior liberdade que os princípios proporcionam ao intérprete, se comparado aos mitzvot, reside na forma e substância de ambas as categorias legais. Primeiro, as normas cíveis manifestam-se em princípios genéricos que não foram extensamente desenvolvidos pelo direito oral. A interpretação, com isso, tornou-se necessária à definição de regras sociais mais bem definidas. Logo, a principal diferença quanto à forma está no grau de generalidade, característica essa que guarda relação direta com o objeto de cada uma das categorias (LEVINE, 1997, p. 463). Por vezes, os rituais são produto de uma vontade divina de difícil articulação e discernimento, o que limita o exercício 
interpretativo, por mais que a análise do texto ou da lógica interna dos mitzvot abra algum espaço ao leitor.

A vontade divina também é fonte dos princípios. Porém, a interpretação apresenta-se como condição de construção de um sistema jurídico dotado de normas plenamente aplicáveis (LEVINE, 1997, p. 463). A natureza programática dos princípios influi de igual modo sobre a discricionariedade do aplicador: ao passo que não é permitida a limitação da incidência da mitzva sob o pretexto de respeitar à vontade de Deus que lhe dá fundamento, os princípios remetem a um sistema divino, mas racional, que autoriza interpretações mais ampliativas ou restritivas, conforme a vontade divina que lhe confere fundamento.

“A Torá, inobstante toda reverência com que é tratada, nunca é objeto de adoração no judaísmo, mas é por meio da Torá que Deus revela sua vontade ao povo judeu e, por meio dele, a toda humanidade" (JACOBS, 1995, p. 2). A tradição jurídica hebraica afasta qualquer possibilidade de intervenção divina posterior à revelação da Torá a Moisés (ZOHAR, 1995). É neste sentido que o Talmude narra os esforços do Rabino Eliezer em fazer valer seu entendimento da Torá frente ao entendimento majoritário do Conselho de Rabinos ${ }^{4}$. Após recorrer aos mais diversos sinais miraculosos, Eliezer socorreu-se por fim à voz de Deus. Aos Rabinos, Deus questionou qual o problema que o Conselho tinha contra Eliezer, uma vez que a lei era tal qual Eliezer dissera ser. Em resposta, o Rabino Josué recitou o verso 12 do capítulo 30 do Deuteronômio: “Ele [o direito] não está nos céus, para que digas: quem subirá ao céu para buscá-lo por nós e citá-lo para que nós o observemos?" Com esta passagem, pretendia Josué lembrar o próprio Deus de que, a partir do momento em que a Torá fora entregue ao homem no Monte Sinai, os judeus não mais considerariam vozes divinas, em razão de estar determinado na Torá que as decisões devem ser tomadas de acordo com a maioria.

O Rabino, em momento algum, questiona a autenticidade da manifestação divina. A contundência de sua réplica a Deus reside em ser um protesto contra a indevida intervenção a favor de Eliezer. Após narrar essa contenda entre Eliezer, Josué e Deus, o Talmude coloca-se a narrar o encontro entre o Rabino Nathan e o Profeta Elias. Nesta ocasião, perguntou Nathan a Elias qual foi a reação de Deus diante da recusa dos homens em escutar a sua voz, no que lhe respondeu o Profeta que Ele somente sorriu e disse: "Meus filhos ganharam contra mim, meus filhos ganharam"5. A reação de Deus - ou a falta dela - indica um consentimento sobre

\footnotetext{
${ }^{4}$ Talmude, Baba Mezi'a 59b.

${ }^{5}$ Ibid. 
sua exclusão dos processos de determinação do direito após a revelação da Torá. Não restaria espaço a emendas no texto, apenas à interpretação de seu conteúdo (ZOHAR, 1995, p. 309).

A relevância da hermenêutica é bem caracterizada na parábola Seder 'Eliyyahû Zûta, que relata a história de um antigo Rei que dá a dois de seus servos uma determinada porção de farinha e uma determinada extensão de linho. O servo inteligente teria transformado o linho em toalha e a farinha em pão no propósito de preparar a mesa de jantar para a chegada do Rei. Já o menos inteligente, por sua vez, nada teria feito. Ao visitá-los, o Rei exigiu que mostrassem a farinha e o linho, no que o primeiro servo serviu o pão sobre a mesa enfeitada com a toalha e o segundo apresentou somente um cesto com a farinha e o linho. Neste momento, ter-lhe-ia esbravejado o Rei: “Que vergonha! Que desgraça!”. Assim como teria feito o Rei ao dar farinha e linho aos seus servos, fizera Deus ao entregar a Torá aos judeus. A metáfora é ilustrativa: "o que foi recebido de Deus foi entregue como material cru a ser trabalhado e transformado em algo útil. A atitude contrária, de servilmente preservar o presente divino da Torá em sua forma original, é explicitamente caricaturizada" (ZOHAR, 1995, p. 317).

O direito judaico conhece três fontes e métodos de interpretação (LEVINE, 1997, p. 447). Transmitidas oralmente por Deus a Moisés, as interpretações da Torá escrita contidas na Torá oral prescindem de dedução. Os pormenores de leis escritas contidos no Talmude, ainda assim, podem ser classificados em dois grupos distintos. Existem detalhes que não encontram fundamento nas leis escritas, delas não podendo ser deduzidos seja textual ou logicamente. Em casos em que detalhes são necessários à aplicação de leis vagas, o Talmude tão somente prescreve os detalhes para tanto, sem ter o cuidado de explicar suas razões. Por outro lado, existem detalhes que podem ser diretamente traçados à Torá escrita, e assim faz o Talmude ao prescrevê-los. Em segundo lugar, o Talmude prevê diversos métodos de interpretação textual, que no mais das vezes compreendem maneiras específicas de análise literária: "ainda assim, a determinação final sobre qual método aplicar em quais circunstâncias não é sempre aparente, e as conclusões sobre direito são baseadas em uma lógica interna específica a uma arte única e perdida" (LEVINE, 1997, p. 448). Por fim, a lógica e a observação consistem na terceira e última fonte de interpretação, sendo utilizadas para definir a interpretação mais apropriada do texto, inferir um princípio do tex to ou aplicar um princípio previsto a casos não previstos.

Ainda assim, a história judaica testemunhou o surgimento de correntes defensoras da Torá escrita como única base legítima de tradições e costumes da sociedade, repudiando tanto interpretações flexíveis de seu texto quanto interpretações sedimentadas na Torá oral. Assim teriam feito os Saduceus em contraponto aos Fariseus, que passavam adiante as tradições que 
não estavam previstas na Torá escrita, mas somente na oral (GREY, 1984) ${ }^{6}$. Os Saduceus consideravam apenas as leis da Torá escrita como vinculativas, não reconhecendo autoridade na Torá oral. Desta disputa, sagraram-se vencedores os Fariseus, de maneira que o judaísmo rabínico aceitou uniformemente os ensinamentos transmitidos do alto do Monte Sinai.

Além de reconhecer o papel fundamental desempenhado pela interpretação no direito judaico, o Talmude admite a possibilidade de a Torá ser interpretada de formas não só distintas, mas também contrárias. A divergência entre duas leituras igualmente coerentes não impede que ambas reflitam autêntica e igualmente a vontade de Deus (LEVINE, 1997). Uma vez que a hermenêutica tem por objetivo descobrir a vontade divina para questões cujas soluções não são previstas de antemão pela Torá, fonte de todo o direito judaico, é responsabilidade do hermeneuta chegar a resultados que sejam justos aos olhos de Deus. Porém, a pluralidade das possíveis interpretações apresenta ao sistema jurídico judaico um problema de natureza prática, bem antecipado por Nachmánides na virada do século XII para o século XIII: se todas as conclusões coerentes frente à Torá fossem consideradas válidas e, portanto, vinculativas, não existiria uma Torá, mas sim diversas (LEVINE, 1997). Para tanto, fez-se necessária a constituição de uma autoridade interpretativa que, diante de controvérsias e indecisões sobre o significado da vontade divina, decidisse por último.

A tensão entre a incessante busca pelo derradeiro significado da manifestação divina e a necessária adaptação da lei às necessidades práticas da sociedade judaica manifesta-se em princípios do próprio direito judaico (LEVINE, 1997, p. 469). Na passagem do capítulo 17 do Deuteronômio, em seus versos 8 a 10, a Torá ordena que, diante de um caso que não pode ser resolvido, "subirás ao lugar que escolher o Senhor teu Deus; E virás aos sacerdote levitas, e ao juiz que houver naqueles dias, e inquirirás, e te anunciarão a sentença do juízo". Portanto, aos juízes das sucessivas gerações são reconhecidas a legitimidade e a liberdade para interpretar a Torá, não estando condicionados às decisões tomadas pelos juízes das gerações passadas. Dá-se a cada geração de judeus a oportunidade de ressignificar, de acordo com as exigências de sua respectiva época, os ensinamentos passados por Deus a Moisés no Monte Sinai.

\footnotetext{
${ }^{6}$ A seita dos Saduceus foi extinta com a destruição do segundo templo judeu, no ano 70. Portanto, a disputa entre eles e os Fariseus é anterior à compilação da tradição e da sabedoria orais no Talmude. 


\section{O INTÉRPRETE DO CORÃO}

Explica o Corão que Deus revela-se aos indivíduos de três maneiras distintas, porém igualmente extraordinárias (SAEED, 2006). "É inconcebível que Deus fale diretamente ao homem, a não ser por revelações, por intermédio de um véu ou por meio de um mensageiro que, com Sua permissão, revelará o que Lhe apraz"7. A manifestação imediata de Alá recebe a designação de wahy: transmitida diretamente por Ele, a mensagem chega sem intermediações ao fiel, que, ao recebê-la, simplesmente intui a origem divina. A segunda forma de revelação toma forma mediante um véu que, ao mesmo tempo em que permite o pronunciamento, impede que Deus seja vislumbrado pelo indivíduo. A mais tradicional forma de revelação fazse por meio de um mensageiro, a quem Deus entrega a responsabilidade de levar Suas palavras aos homens. A revelação do Corão, no século VII, foi, segundo os teólogos muçulmanos, realizada por Gabriel, anjo responsável por levar a mensagem de Alá a Maomé (SAEED, 2006).

Recebido pelos fiéis como a mensagem sagrada e imutável de Alá, o Corão é o texto sagrado do Islã. Seus 114 capítulos, cuja extensão varia e cujo título remete ao seu assunto ou às suas primeiras palavras, classificam-se como mecanos ou medinos, conforme o momento em que foram revelados a Maomé: se antes ou depois da migração do Profeta à cidade de Medina. O monoteísmo representa o principal assunto do Corão, que eleva Deus à qualidade de entidade onisciente e onipotente: “Alá - não há nenhuma divindade além d'Ele, o Eterno Vivente, o Sustentador de toda existência (...). Ele conhece tanto o passado como o futuro e os seres humanos nada conhecem de Sua Sabedoria, com exceção do que Ele permite"8.

Uma leitura atenta do Corão revela que as matérias estritamente jurídicas são objeto de um pequeno número dos seus versos que, variando de acordo com o entendimento sobre o que seria "matéria estritamente jurídica", oscilam entre 80 e 500 (SAEED, 2006, p. 65). Ainda que trabalhada com a estimativa mais positiva, 200 versos tratam apenas de questões pessoais, ao passo que a maioria dos 500 versos dispõe sobre adorações e rituais, ambos essenciais ao direito islâmico. Contratos e crimes carecem de pormenorizações, revelando que o Corão, em sua natureza, não almeja ser um documento jurídico. No geral, seus versos ocupam-se com a exposição dos dogmas básicos do Islamismo, como a existência de Deus e sua ressurreição, e

\footnotetext{
${ }^{7}$ Corão, 2:23. Tradução livre.

${ }^{8}$ Corão, 2:255. Tradução livre.
} 
também trazem narrativas sobre a vida de antigos profetas e sobre acontecimentos históricos da época do Profeta Maomé.

Em determinadas passagens, exorta o Corão: “Obedecei a Deus e ao Mensageiro! Mas, se se recusarem, saibam que Deus não aprecia os incrédulos" ". Na medida em que Alá comanda os fiéis a seguirem o exemplo de Maomé em vida, seus ensinamentos, práticas e interpretações revestem-se de uma natureza normativa na sociedade muçulmana. $\mathrm{O}$ estilo de vida do Profeta é posteriormente registrado na Suna, que, ao lado do Corão, passa a constituir a fonte primária do direito islâmico: a Charia. Ambas as fontes, entretanto, não contêm regras específicas, mas indicações e observações a orientar a tomada de decisões. Para tomá-las em consonância com os mandamentos da Charia, deve o intérprete valer-se de parâmetros tais quais os consensos, as analogias, as doutrinas, os precedentes e os interesses públicos. Resguardadas as respectivas particularidades, estes procedimentos compreendem formas de $i t j h \bar{a} d$, que nada mais é do que o exercício mental destinado à busca da resposta a tal ponto que o jurista torna-se incapaz de realizar maior esforço (HALLAQ, 1984). Precisamente, itjhād compreende "a soma dos esforços despendidos pelo jurista no intuito de inferir, com algum grau de probabilidade, as regras da Charia a partir das detalhadas evidências nas fontes" (KAMALI, 1991, p. 366).

A diferença crucial entre a itjhād, o Corão e a Suna reside na dinamicidade da fonte. Enquanto as revelações de Alá e os ensinamentos de Maomé naturalmente terminaram com o falecimento do Profeta em 632, a interpretação apresenta-se como um processo em constante desenvolvimento, condição esta que torna a itjhād a principal ferramenta de interpretação do texto sagrado e de diálogo entre a mensagem divina e as contingências da sociedade islâmica e de suas perspectivas de justiça, salvação e verdade (KAMALI, 1991).

A adequação da $i t j h \bar{a} d$, cujo exercício é legitimado pela própria revelação divina, está condicionada à sua harmonia diante do Corão e da Suna: "A unidade essencial da Charia reside no grau de harmonia que é conquistado entre revelação e razão. A Itjhād é o principal instrumento na manutenção desta harmonia” (KAMALI, 1991, p. 336). Seu fundamento legal encontra-se previsto na hadith sobre Mu'ad ibn Jabal, um jovem da cidade de Medina (HOLT; LAMBTON; LEWIS, 1970, p. xv $)^{10}$. Quando questionado pelo Profeta sobre como decidir no caso concreto, Jabal afirmou que decidiria em sintonia com os ensinamentos do Corão. Em seguida, Maomé questionou como Jabal procederia caso nenhuma decisão prévia pudesse ser

\footnotetext{
${ }^{9}$ Corão, 3:32. Tradução livre.

${ }^{10} \mathrm{O}$ hadith consiste nos memoriais dos supostos atos e dizeres do Profeta que foram, posteriormente à sua morte, relatados e compilados por uma cadeia de informantes.
} 
encontrada no Corão. Nessas situações, respondeu o jovem, deveria a Suna ser a base para as decisões. Mas, se nem a Suna apresentasse respostas - provocou Maomé -, como decidir? Jabal, em sua tréplica, agradou ao Profeta ao afirmar que decidiria a partir do exercício incansável de seu intelecto (QURAISHI, 2006) ${ }^{11}$.

A prática da itjhād figurava como principal objetivo da metodologia do usul al-fiqh, a teoria do direito islâmico. Elaborada a partir da necessidade de descobrir quais as decisões de Alá, seu objetivo era formular um sistema coerente de princípios que auxiliasse o jurista a encontrar soluções novas a problemas novos, mantendo o respeito aos ensinamentos do Corão (HALLAQ, 1984). Os três primeiros séculos islâmicos foram testemunhas da resistência à prática da itjhād por escolas do direito islâmico presas ao hadith e preocupadas em interpretar ao pé da letra as fontes reveladas. Dentre as madhhabs (escolas) tradicionalistas, bem heterogêneas entre si, a Zahiri exerceu uma significativa influência ao defender a restrição do jurista aos significados literais ou aparentes das revelações. Acreditava-se isolar o direito das puras especulações do intérprete, que constituiriam em última análise a verdadeira natureza da $i t j h \bar{a} d$. Assim, todo e qualquer exercício interpretativo era negado como uma atividade falível e incerta - como uma articulação ilegítima da vontade de Deus (MELCHERT, 1997).

Inobstante a reputação pela inflexibilidade e rigidez, a doutrina Zahiri posicionava-se de maneira ambivalente, defendendo pontos de vista ora conservadores, ora liberais. No geral, sua metodologia alcançou resultados mais ou menos permissivos que os resultados alcançados pelas demais madhhabs, por mais que demonstrasse um forte potencial para ser uma teoria ativista, reformista e historicista (QURAISHI, 2006). Contudo, a rejeição categórica à itjhād, sobretudo à analogia, terminou por conduzir a escola Zahiri ao ostracismo intelectual nas comunidades muçulmanas sunitas, que não abrigavam escolas contrárias à itjhâd como elemento formador do direito islâmico (HALLAQ, 1984).

São significativas, neste contexto aberto à interpretação, as transformações sofridas pela escola Hanbali (HALLAQ, 1984). De raízes teológicas e visões formais sobre o

\footnotetext{
${ }^{11}$ Não há como o mujtahid (jurista que pratica a itjhād) saber em vida se articulou corretamente a lei divina. Essa circunstância, porém, em nada desfavorece a prática da itjhād. De acordo com o Hadith n. 4261, assim ensinou Maomé: "Quando um juiz profere uma decisão e acerta, tendo se esforçado ao máximo para decidir corretamente, a ele são concedidas duas recompensas. Quando um juiz profere uma decisão e erra, tendo se esforçado ao máximo para decidir corretamente, a ele é concedida uma recompensa". Desta passagem, duas conclusões podem ser extraídas. Primeiro, o jurista cumpre seu dever perante Deus simplesmente ao praticar a itjhād, não importando se chegou ou não ao resultado correto. Caso a resposta certa seja alcançada, há um bônus. Em segundo lugar, o mujtahid interpretará o texto a partir do pressuposto de que opiniões contrárias às suas podem ser, ao final, corretas. "A realidade conduz ao resultado prático de que qualquer resultado da ijtihad [itjhād] carrega consigo legitimidade ao ser, em potência, uma articulação verdadeira do direito de Deus" (QURAISHI, 2006, p. 71).
} 
fenômeno jurídico, à escola sequer era reconhecido o status de uma autêntica madhhabs, sendo a expertise jurídica de ibn Hanbal por diversas vezes questionada e criticada. Aproveitando-se da ascensão da teoria sunita, representada por excelência pelas escolas de Shafi'i e Hanafi, o hanbalismo colocou-se sob a égide dessas duas doutrinas e acrescentou credenciais jurídicas às suas credenciais teológicas. A escola Hanbali, com isso, passou a vislumbrar na analogia uma fonte de direito quase tão relevante quanto os textos do Charia e os eventuais consensos da sociedade islâmica. As concessões de Ibn Hanbal à interpretação humana deram-se apenas por conta da pressão sofrida pelas demais escolas e, sempre que possível, era nas escrituras que procurava por soluções. "Com o intuito de sobreviver ao Sunismo, o Hanbalismo precisou enfrentar um processo de moderação e mudança de um grupo teológico extremista a uma escola de direito particularmente moderada, ainda mantendo alguma inclinação teológica" (HALLAQ, 1984, p. 10).

Ao fim do processo de adaptação da escola, consolida-se uma abordagem teleológica pautada sobretudo pelo interesse público (GOOLAM, 2006). Segundo a doutrina de Ibn Hanbal, a preocupação com o bem da coletividade fazia-se presente nas interpretações dos companheiros de Maomé que, após a morte do Profeta em 632, ficaram responsáveis por difundir a mensagem do Corão. Uma ainda maior autoridade era atribuída aos entendimentos desses discípulos pela escola Maliki, para a qual os costumes presentes na cidade de Medina na época do Profeta gozariam de superioridade absoluta na compreensão das passagens contidas na Charia, uma vez que "as palavras e as ações do Profeta não poderiam ser entendidas isoladamente sem também levar em consideração o contexto em que elas ocorreram" (QURAISHI, 2006, p. 92).

Para Malik ibn Anas, a partir de quem a escola recebeu seu nome (SAEED, 2006) ${ }^{12}$, as práticas e opiniões da sociedade de Medina trariam consigo o exemplo fiel do direito divino, exemplificando o ideal de sociedade islâmica em razão de seu povo ter testemunhado diariamente a revelação divina e seu cumprimento por Maomé e seus sucessores (QURAISHI, 2006, p. 90). De início, a escola Malik baseava-se nas narrativas sobre costumes, na doutrina dos mais importantes juristas e na jurisprudência dos califas. Entretanto, conclusões diversas eram alcançadas por seus afiliados em virtude de pesos distintos serem conferidos às fontes (GOOLAM, 2006). Diante desta flexibilidade, Imam Al-Shafi'i defendia o retorno ao exemplo

\footnotetext{
12 Assim como as escolas Zahiri e Hanbali, respectivamente nomeadas a partir de Dawud ibn Khalaf al-Zahiri e ibn Hanbal, a corrente fundada por Malik ibn Anas terminou por levar seu nome. Na passagem do século X ao século XI, afirmava-se a crença na cultura e prática islâmica de que aos fiéis caberia somente seguir os ensinamentos consolidados pelos grandes fundadores das diferentes escolas do direito. Revista da Faculdade de Direito - UFPR, Curitiba, vol. 59, n. 2, p. 47-73, 2014.
} 
pessoal de Maomé: "Shafi'i insistia que existe uma diferença qualitativa entre a hadith do Profeta e as práticas diárias dos descendentes de seus companheiros em Medina. De forma sucinta, a primeira era de inspiração divina e a última, não" (QURAISHI, 2006, p. 93). Assim, Shafi'i opunha-se à premissa dos costumes medinos serem indicadores do significado verdadeiro da lei divina.

Com a chegada do século XI, a teoria interpretativa proposta por Shafi'i expandiu-se para adotar posturas mais flexíveis em relação à ijtihad. Competiu a Abu Hamid al-Ghazali romper com o dogma da escola Shafi'i de que aceitar como fontes autorizadas de direito as compreensões humanas seria um equívoco teórico. A articulação promovida por Ghazali, quase que um consenso dentro da teoria do direito islâmico, apontou cinco objetivos últimos das leis da Charia: religião, vida, razão, família e propriedade. Toda e qualquer norma jurídica poderia ser traçada a um desses objetivos que, quando juntos, promoveriam e constituiriam o bem comum. A adequação assume um papel fundamental em seu método interpretativo, que consistia em um exercício de analogia entre a decisão tomada no caso concreto e os cinco propósitos derradeiros: "o que estiver em conformidade com os propósitos da lei é adequado e, logo, um direito legítimo, e o que não se conformar a esses propósitos está fora do conjunto das decisões jurídicas islâmicas aceitáveis” (QURAISHI, 2006, p. 102).

A ijtihad ocupou uma posição central nos esforços teóricos e práticos dos mujtahids Ibn Hanbal, Malik ibn Anas e Abu Hamid al-Ghazali. Por mais que cada um tenha formulado estratégias para lidar com as particularidades das respectivas conjunturas históricas, a razão do jurista foi um instrumento por todos igualmente utilizado na incansável e infindável busca pelas leis da Charia. Como acontecia em séculos passados, os textos sagrados do islamismo não providenciam respostas imediatas às questões impostas pelo século presente. A noção de que as regras ético-jurídicas contidas no Corão e na Suna devem ser contextualizadas faz-se presente contemporaneamente (SAEED, 2006). Quando se dirigiu a Maomé por meio do anjo Gabriel, Alá revelou sua vontade para uma sociedade específica - os muçulmanos do século VII que habitavam a cidade de Hejaz. Logo, a aplicação dos mandamentos do Corão às gerações de muçulmanos que procederam ao Profeta e que vivenciam contextos históricos bem diversos conduz a resultados que levam à reflexão sobre o lugar dessas instruções nesse novo contexto que a Charia pretende regular. "Se este é o caso, alguém pode argumentar que cada geração pode chegar a entendimentos sobre as instruções ético-jurídicas do Corão que podem divergir dos entendimentos de gerações anteriores" (SAEED, 2006, p. 20). 


\section{O INTÉRPRETE DA CONSTITUIÇÃO}

Pouco antes de a atual Constituição dos Estados Unidos entrar em vigor, em março de 1789, o Segundo Congresso Continental instituiu uma comissão responsável por elaborar uma lei em comum às 13 colônias, à época engajadas na guerra de independência contra o Império Britânico. Concluídos em 1777 e entrando em vigência apenas em março de 1781, os Artigos da Confederação eram reflexo fiel da experiência constitucional vivida nos estados marcada principalmente pela desconfiança em relação ao Poder Executivo e pela supremacia do Poder Legislativo (PAIXÃO; BIGLIAZZI, 2011). Logo, seus treze artigos "destinavam aos Estados independentes a expressiva maioria do poder político e econômico, deixando matérias muito gerais à apreciação do Congresso" (PAIXÃO; BIGLIAZZI, 2011, p. 137) ${ }^{13}$.

Antes do fim da guerra e da vigência dos artigos, a recém-constituída Confederação mostrava-se impotente diante das turbulências administrativas e econômicas no âmbito nacional, bem como dos faccionalismos e das rivalidades em âmbito local. Em razão da crise fiscal que se abateu tanto sobre os estados, com surtos inflacionários a corroer o valor da moeda e a elevar o valor da dívida, quanto sobre o país, com a dificuldade de honrar os compromissos externos contraídos por conta da guerra, a animosidade dos devedores não tardou em produzir conflitos sociais. Encorajados pela inércia do Poder Legislativo estadual, paralisado pelas divergências entre lideranças políticas, a luta dos devedores pelo refinanciamento e perdão da dívida tomou rumos violentos. Se somados à crise militar e às ameaças externas, percebe-se a "sucessão de eventos - não planejados e, em grande medida, insuscetíveis - que impulsionou o movimento de redefinição das bases da União" (PAIXÃO; BIGLIAZZI, 2011, p. 139).

Foram justamente questões locais que serviram de plataforma para o lançamento de propostas em âmbito nacional. A concepção de um governo central forte surge entre ativistas políticos de Nova Iorque, que defendiam, com o fim de combater a crise financeira e as revoltas locais, a instituição de uma dívida pública nacional e de um banco nacional, além de meios de fomento da colaboração dos estados com as políticas nacionais. Entretanto, as tentativas de reforma encontraram obstáculo no difícil processo de emenda previsto pelos Artigos da Confederação, que estipulava sua aprovação por todos os treze estados membros. A Convenção Constitucional que forjou a atual constituição americana foi instalada a partir da

\footnotetext{
13 À União recém-constituída eram atribuídas funções essencialmente de diplomacia, como declaração de guerra e celebração de paz, bem como funções de defesa comum. Não lhe era permitida sequer a manutenção de um exército.
} 
disputa entre os estados de Maryland e Virgínia sobre a administração do rio Potomac. O diálogo, entretanto, expandiu-se e incluiu outros estados, de tal forma que se decidiu pela realização de uma convenção com o fim de "emendar os Artigos da Confederação para constituir um governo federal compatível com as necessidades da União" (PAIXÃO; BIGLIAZZI, 2011, p. 142).

Os trabalhos da Convenção Constitucional começaram em maio de 1787, passando pelas mais diversas questões, como economia, federalismo e defesa. George Mason, delegado do estado da Virgínia, suscitou a discussão sobre emendas constitucionais ao frisar que, assim como os Artigos da Confederação, a Constituição ali escrita também poderia revelar-se inapta para lidar com momentos de especial dificuldade. Portanto, diante de sua imprescindibilidade, melhor seria prevê-las de forma "fácil, regular e constitucional" do que deixá-las a cargo da oportunidade e da violência (FARRAND, 1937, p. 202-3). Se as revoluções compreendem a forma mais radical de desenvolvimento da ordem jurídica e consistem em transformações cuja profundidade é tamanha que não guarda nenhuma relação com a ordem prévia (LEVINSON, 1995b, p. 21), as emendas apresentam-se como a institucionalização da ideia de revolução, na medida em que são disciplinadas pela ordem constitucional (WOOD, 1969).

Todavia, a adoção de mecanismos de emenda constitucional não era ponto pacífico entre os constituintes e seu emprego no correr da história suscitou calorosos debates - entre eles, o travado entre James Madison e Thomas Jefferson por ocasião da incorporação de um Bill of Rights à Constituição. Além de crer que a inclusão de direitos e limitações legais à ação do governo instituísse somente limites em papel, apostando no poder do Congresso de vetar as leis estaduais e no poder de um conselho formado pelos Poderes Executivo e Judiciário de vetar as leis federais (HAMILTON; JAY; MADISON, 2007, p. 378), Madison mostrava-se particularmente inclinado a atribuir maior imutabilidade ao texto constitucional, sob o argumento de que, "como todo apelo ao povo traria a implicação de algum defeito no governo, apelos frequentes, em grande medida, privariam o governo daquela veneração que o tempo a tudo confere e sem a qual o mais sábio e livre dos governos talvez não possuiria o requisito da estabilidade" (HAMILTON; JAY; MADISON, 2007, p. 386). Em contrapartida, Thomas Jefferson defendera, em correspondência endereçada ao próprio James Madison, que 
e o que dela advier, durante seu usufruto. Eles são senhores também de si mesmos e, consequentemente, podem governar-se como quiserem ${ }^{14}$.

A modificabilidade das regras constitucionais, mediante um processo legal previsto no texto a ser modificado, fez-se pela primeira vez presente nas experiências constituintes dos estados. A primeira constituição de Nova Jersey, adotada no ano de 1776, previa - ainda que implicitamente - mecanismos de emenda. Coube ao estado da Pensilvânia, cuja primeira constituição também data de 1776, elaborá-los explicitamente. As emendas seriam elaboradas por convenções constituintes e, em seguida, submetidas à aprovação de ambas as casas do congresso estadual. Ao final do século XVIII, consolidado o princípio de que a Constituição poderia ser pontualmente emendada pela vontade popular, quase a metade dos estados norteamericanos possuía algum procedimento de emenda (LUTZ, 1995). Na Convenção Constitucional da Filadélfia decidiu-se disciplinar o processo de emenda por intermédio do artigo $5^{\circ}$ da Constituição, que dispõe sobre seu texto poder ser emendado mediante a proposta de dois terços das Casas do Congresso dos Estados Unidos ou de convenção convocada por dois terços das legislaturas estaduais (LEVINSON, 1995a). Para tornar-se emenda, a proposta deve ser ratificada por três quartos dos estados ou por três quartos da Convenção.

O processo de emenda é um processo decisório público, formal e deliberativo, que traça a distinção entre questões constitucionais e questões ordinárias (LUTZ, 1995) ${ }^{15}$. “As pressuposições que subjazem à noção de emenda exigem que o procedimento não seja nem muito fácil e nem muito difícil” (LUTZ, 1995, p. 240). Se for fácil demais, o processo equipara matérias constitucionais e ordinárias, comprometendo o nível de deliberação pública e banalizando o exercício da soberania popular. Se for difícil demais, o processo prejudica a necessária retificação de equívocos e de lacunas, ignorando a falibilidade da natureza humana e obstaculizando o exercício da soberania popular.

Desde sua promulgação, 27 emendas foram acrescentadas ao texto da Constituição. Dez delas foram promulgadas em seguida, em 1791, constituindo o chamado Bill of Rights. A última emenda foi inserida no ano de 1992, muito embora sua proposta tenha sido apresentada em 1789. O baixo número de emendas reflete a burocracia exigida pelo processo estipulado

\footnotetext{
14 Thomas Jefferson foi adiante, chegando a sugerir que as constituições expirassem passados dezenove anos de sua promulgação. James Madison posteriormente convenceu-se sobre a inclusão do Bill of Rights, passando a considerá-lo instrumento de conscientização das maiorias políticas que, diante de violências cometidas por seus representes à Constituição, tomariam as medidas políticas necessárias para puni-los (THE FOUNDERS' CONSTITUTION, 2000, p. 68).

15 As quatro principais premissas do processo de emenda seriam: i) a soberania popular; ii) a falibilidade e a educabilidade da natureza humana; iii) a eficácia do processo deliberativo; e iv) a distinção entre matéria constitucional e legislação ordinária.
} 
pelo artigo $5^{\circ}$, cuja complexidade possui o condão de fazê-lo um difícil meio de mudança e adaptação. As emendas, todavia, prestam-se a outras duas funções (STRAUSS, 2010). Primeiro, funcionam de ponto de partida para a resolução de questões que, mesmo não sendo controvertidas, devem ser decididas definitiva e inequivocamente. É esta a função cumprida, por exemplo, pela $25^{\mathrm{a}}$ Emenda, ao pontuar os ritos de vacância e sucessão presidenciais. Em segundo lugar, como meio de uniformização de compreensões e de supressão de divergências. Quando a sociedade estiver próxima de chegar a um consenso sobre certo assunto, o processo formal de emenda traz os retardatários em linha e "torna o quase consenso unanimidade" (STRAUSS, 2010, p. 115). Assim fez a 24 Emenda ao banir a cobrança de taxas em eleições federais. À época de sua promulgação, apenas quatro estados condicionavam o voto à taxa. Portanto, há transformações realizadas pelas emendas, ainda que mínimas.

Na redação da Constituição, os constituintes valeram-se de uma linguagem aberta que, concedendo aos intérpretes liberdade, tornou possíveis emendas por intermédio da interpretação. Diante das ambiguidades textuais, emendas dessa natureza consistiriam em nada mais do que determinações de sentido (LUTZ, 1995). As disposições constitucionais formais nem sempre trazem consigo um único sentido, mas sim um feixe de possíveis interpretações que, estando imanente ao texto, possui igual legitimidade. Na decisão em Marbury v. Madison, o Chief Justice John Marshall ressalta a importância de uma constituição escrita, considerada por ele o mais importante avanço institucional promovido pelos Estados Unidos ao especificar e limitar os poderes do governo. "O problema, claro, é como decidir discussões sobre o que a 'escrita' de fato significa" (LEVINSON, 1995b, p. 23).

Outra relevante decisão da Suprema Corte, ainda sob a Presidência de Marshall, deuse no julgamento de McCulloch v. Maryland, quando foi questionada a constitucionalidade do Segundo Banco dos Estados Unidos. Inobstante Marshall ter se pronunciado apenas sobre o Segundo Banco, a decisão pode ser compreendida como um parecer de que o Primeiro Banco, ao contrário do entendimento de James Madison, para quem a Constituição não autorizava o Congresso a criar um banco nacional, também era constitucional (LEVINSON, 1995b). A relevância da decisão reside no amplo feixe de leis que, a partir de McCulloch v. Maryland, poderia ser promulgado pelo Congresso, em razão da igualmente ampla leitura de Marshall, "que se aproveitou da oportunidade para delinear uma teoria abrangente sobre os poderes nacionais que pode ser concebida como basicamente atribuindo autoridade absoluta ao Congresso" (LEVINSON, 1995b, p. 22). Nas palavras do Chief Justice, em seu voto, o mérito 
da decisão estaria em revelar uma constituição a durar indefinidamente e, por consequência, a ser adaptada às diversas crises dos affairs humanos ${ }^{16}$.

A leitura de Marshall "parece ser menos uma interpretação da Constituição do que uma emenda a ela, cuja reversão é inimaginável” (WHITE, 1985, p. 263). Inovações em sede de decisões judiciais não foram, porém, sua exclusividade, sendo também realizadas em diversas oportunidades. Mas, com Marbury, foi inaugurado um modelo de revisão judicial em que cada Poder é responsável por aferir a constitucionalidade apenas dos atos dos demais Poderes que venham a interferir em seu adequado funcionamento. Embora seja difícil precisar, essa prática de controle judicial de constitucionalidade perdeu-se entre o final do século XIX e meados do século XX (TUSHNET, 2003). Em 1958, ao decidir Cooper v. Aaron, a Suprema Corte sentir-se-ia à vontade para frisar que o Poder Judiciário seria supremo na exposição do direito constitucional, pronunciando decisões vinculantes a todos os estados e Poderes, ainda que não concordassem com seu conteúdo.

A proeminência conquistada pela Suprema Corte no cenário institucional culminou na centralização da interpretação constitucional na figura do Poder Judiciário. A dificuldade contramajoritária colocada por Alexander Bickel (1962), em virtude da natureza não democrática do Poder Judiciário, direcionou o foco da discussão em direito constitucional ao método de interpretação que, se empregado pelos juízes, compatibilizaria regime democrático e jurisdição constitucional ${ }^{17}$.

Assim como em Cooper v. Aaron, a Suprema Corte continuava sob a presidência de Earl Warren à época da polêmica decisão de Roe v. Wade. Entre 1953 e 1969, quando liderada por Earl Warren, a jurisprudência da Corte caracterizou-se por um ativismo judicial de feições esquerdistas (FRIEDMAN, 2004). Por sete votos contra dois, a Corte determinou que o direito à privacidade, garantido pela cláusula do devido processo da $14^{\mathrm{a}}$ Emenda, abrange o direito da mulher ao aborto, desde que realizado ainda no primeiro trimestre de gravidez. Ao declarar a inconstitucionalidade das leis federais e estaduais que restringiam o acesso a serviços abortivos, o julgado estimulou um amplo debate público que pôs em questão não só o aborto, mas também o papel político e institucional cumprido pela mais alta Corte.

\footnotetext{
16 SUPREME COURT OF THE UNITED STATES, 1819.

${ }^{17}$ A conhecida dificuldade contramajoritária manifesta-se no veto do Poder Judiciário, cujos membros não estão sujeitos à accountability das urnas, a atos normativos dos Poderes Executivo e, principalmente, Legislativo. É na principal competência do controle judicial de constitucionalidade que reside seu problema e, ao exercê-la, as cortes constitucionais evidenciam a intrínseca tensão entre constitucionalismo e democracia. Seguindo essa linha, a revisão judicial revela-se um obstáculo antidemocrático à fiel manifestação da soberania popular, impondo a vontade de poucos juízes sobre a decisão dos representantes do povo.
} 
Antes de Roe v. Wade, a cláusula do devido processo já era interpretada para conferir proteção a direitos individuais - sobretudo a direitos previstos no Bill of Rights. Assegurados pela Corte em oportunidades anteriores e posteriores a Roe, os valores da integridade pessoal e da autonomia familiar encontravam abrigo junto às tradições da common law (STRAUSS, 2010). Ao lado das tradições, os precedentes desempenhariam um papel central na evolução da Constituição. A insuficiência do processo de emenda previsto no artigo $5^{\circ}$ inevitavelmente levaria à teoria da Living Constitution, sob risco de seu texto tornar-se ou irrelevante, sendo ignorado pela sociedade que deveria reger, ou paralisante, engessando a sociedade com a qual deveria evoluir. A evolução de tradições e precedentes, meios de mudança constitucional que constituem a Constituição viva, revelar-se-iam da maior importância.

O termo Living Constitution foi empregado, pela primeira vez, na opinião do Justice Oliver Wendell Holmes, em State of Missouri v. Holland. Liderando as críticas e as alterações da jurisprudência da Corte à época de Lochner v. New York, atentava-se à circunstância de que novos tempos exigiam novas doutrinas e que o direito seria fruto de experiências sociais (ALEINIKOFF, 1987) ${ }^{18}$. Em seu voto, ponderara Holmes que:

(...) quando estamos lidando com palavras que são também um ato constituinte, como é a Constituição dos Estados Unidos, devemos perceber que elas levaram à vida um ser cujo desenvolvimento não poderia ser previsto por completo nem mesmo pelos seus mais brilhantes criadores ${ }^{19}$.

Ao utilizarem-se de uma linguagem aberta, os founding fathers deixaram às gerações posteriores o dever de interpretar e aplicar os dispositivos constitucionais a um ambiente em constante transformação. Mais do que uma licença, sua redação em termos abertos consistiria em uma autorização às gerações a compatibilizar as disposições constitucionais a situações que não poderiam ser originalmente previstas na Convenção Constitucional de 1787.

Admirada por constitucionalistas liberais da década de 1950, a Corte Warren despertou os conservadores para a dificuldade contramajoritária por trás da jurisdição constitucional, até então considerada por eles como proteção maior de liberdades e garantias fundamentais. Suas críticas à Warren Court convergiram na corrente interpretativa do

\footnotetext{
${ }^{18}$ Foram três as principais críticas à metodologia constitucional até então empregada na Corte na Lochner Era. No aspecto político, as críticas foram representadas por Franklin Roosevelt, que defendia que a Corte, cujas decisões ativistas e conservadoras bloqueavam as medidas do New Deal, retornasse à Constituição. A questão não residia no texto constitucional, mas nos intérpretes e nos métodos de interpretação: se interpretada adequadamente, a Constituição daria as respostas corretas. No aspecto judicial, as mudanças sociais e econômicas evidenciaram a obsolescência das categorias originalistas fundamentadas sobre noções de direitos individuais e de federalismo que faziam sentido apenas no século XIX. A crítica acadêmica, vocalizada por Oliver Wendell Holmes e Roscoe Pound, assumiu tom semelhante. Para Benjamin Cardozo, à criatividade social e à sensibilidade admitia-se um papel na aplicação do direito.

${ }^{19}$ SUPREME COURT OF THE UNITED STATES, 1920. 
originalismo. Ao ler a Constituição, os justices deveriam fazê-lo de acordo com o sentido originalmente conferido pelos constituintes às disposições do texto (STRAUSS, 2010). Seria necessário que os valores que animaram James Madison e os demais presentes na Convenção Constitucional fossem resgatados pelos juízes ao decidirem as questões apresentadas à Corte. No julgamento de Roe $v$. Wade, cujas críticas alimentaram em boa parte a corrente originalista, argumentou-se que a Corte impõe sobre o texto da Constituição suas preferências políticas. Evitando entrar no mérito do aborto, Antonin Scalia, juiz da Suprema Corte e um dos principais expoentes do originalismo, assim colocou a questão: "Não me diga que o povo americano exige que você o tenha [o direito ao aborto] e o escreveu na Constituição, porque isso não é verdade" (HO, 2012).

A decisão da Suprema Corte em Griswold v. Connecticut foi importante precedente, pavimentando o caminho a Roe v. Wade ao assegurar à mulher o direito de utilizar métodos contraceptivos. As considerações de Hugo Black neste julgamento fazem-se relevantes, já que evidenciam uma forma de interpretar a Constituição que, ao contrário da Living Constitution ou do originalismo, revela-se ambivalente em seus resultados (QURAISHI, 2006). Enquanto seus companheiros de Corte convergiram em relação à inconstitucionalidade da lei que proibia o uso de métodos contraceptivos, ainda que divergissem nos fundamentos para tanto, Black recusou-se a estender as proteções constitucionais além de seu significado literal: "a legislação de Connecticut, como aplicada no caso, não é proibida por qualquer disposição da Constituição como ela fora escrita" ${ }^{20}$. Seu receio, assim como dos originalistas, era de que o texto fosse reescrito por juízes, sob o pretexto de interpretação (GERHARDT 1994).

Seu literalismo defendia que as vedações claramente expressas no texto sem qualquer ressalva, como a proibição ao Congresso de editar lei restringindo a liberdade de religião ou de imprensa, como previsto na $1^{\mathrm{a}}$ Emenda, seriam obstáculo intransponível a toda e qualquer intervenção do Estado (GERHARDT 1994). Dessa maneira, Black chegava a resultados um tanto quanto rígidos, que, todavia, não implicavam uma postura ideológica conservadora muito pelo contrário. A defesa incondicional da natureza absoluta das proibições contidas na Constituição, na igual medida em que restringia a esfera de discricionariedade do Poder Judiciário, atribuía às cortes a função de resguardá-las. Sua doutrina reservava uma especial função à Suprema Corte no que dizia respeito a áreas do texto cujo significado não despertava dúvida. Na mitologia jurídica norte-americana, Black é associado a medidas socioeconômicas 
progressivas adotadas no New Deal e ao ativismo judicial a favor dos pobres e marginalizados (GERHARDT 1994).

Um apanhado histórico das manifestações e reações à dificuldade contramajoritária sugere a conclusão de que liberais e conservadores prezam ou condenam a atuação do Poder Judiciário conforme suas opiniões imediatas (FRIEDMAN, 2004). O resultado em curto prazo dessa consideração é que ambas as correntes revezam-se no posicionamento acerca da revisão judicial: ora favoráveis, ora contrários. A aposentadoria de Earl Warren e a ascensão de Warren Burger à Presidência repercutiu na jurisprudência da Suprema Corte, que, se antes revelava feições esquerdistas, revelou-se eclética o suficiente para não promover maiores retrocessos à agenda liberal. Nesse momento, somente detalhes do instituto do judicial review eram criticados pelos liberais, que em nada questionavam sua essência.

Entretanto, no começo de 1994, a Corte adotou um ativismo judicial crescentemente conservador, exercendo um maior controle sobre os atos do Congresso. Foi especialmente no termo 2002-2003 ${ }^{21}$, na Rehnquist Court, que as decisões judiciais mostraram-se contrárias às ações do Congresso, ao regime constitucional do New Deal, aos réus criminais e às minorias. Por outro lado, direitos de propriedade e direitos federativos receberam proteção judicial. O descontentamento conservador, primeiramente sentido em 1950, encontrou seu fim apenas em 2002, com um ativismo judicial que agradou setores mais conservadores da sociedade norteamericana, embora as expectativas tenham sido inicialmente negativas. Com Bush v. Gore, a Corte extrapolou os limites liberais e passou a sofrer fortes críticas. A novidade está não nas críticas voltadas ao conteúdo das decisões, mas sim nos questionamentos acerca de seus fundamentos e na natureza extrema dos remédios propostos pelos críticos liberais (FRIEDMAN, 2004), como reformas estruturais e novos parâmetros para a prática da revisão judicial. A raiz da crítica liberal contemporânea passou a residir na reivindicação da Suprema Corte como a única intérprete do texto constitucional.

\section{OBSERVAÇÕES FINAIS}

Não são incomuns referências negativas à teologia no discurso jurídico, sobretudo no discurso constitucional. Fazendo eco à crítica de Ingeborg Maus às interpretações valorativas e arbitrárias dos Ministros do Tribunal Constitucional Federal da Alemanha, Gisele Citadino faz menção à teologia constitucional ao criticar a judicialização da política e o protagonismo

\footnotetext{
${ }^{21}$ Cf. Legal Information Institute of the Cornell University Law School. Highlights of the Supreme Court's 2002 2003 term. Disponível em: <http://www.law.cornell.edu/supct/03highlts.html>. Acesso em: 16 ago. 2012. 
das Cortes Constitucionais na democracia contemporânea (CITTADINO, 2004). Em sentido semelhante colocou-se Antonin Scalia, justice da Suprema Corte dos Estados Unidos, ao equiparar os juízes aos mulás ${ }^{22}$, condenando a intervenção dos tribunais em controvérsias morais, como aborto e união homoafetiva (FRANK, 2013).

A verdade é que a denominada teologia constitucional, concebida como crítica à banalização da principiologia e da ponderação de valores, ou o denominado juiz-mulá, concebido como crítica à proeminência do magistrado na definição dos valores sociais, não cumprem o propósito de criticar a arbitrariedade e o descompromisso do Poder Judiciário em interpretar a Constituição. Como ilustrado pela narrativa sobre as disputas no direito judaico e islâmico sobre qual o método hermenêutico mais apropriado para a fiel interpretação do texto sagrado, a discussão hermenêutica na teologia é igualmente norteada pelo debate sobre os limites e métodos de interpretação, assim como é no direito. Há, portanto, uma multitude de escolas e de teorias interpretativas que não pode ser reduzida à teologia, como se este genérico conceito implicasse automaticamente um método que autoriza o intérprete a extrair do texto a interpretação que melhor lhe convier - justamente a crítica dirigida por Ingeborg Maus à jurisprudência de valores, que, de certa forma, poderia ser associada a uma parcela do que o senso comum teórico denomina de neoconstitucionalismo, que, com todas as possíveis ressalvas ao conceito, atribui um papel de destaque à interpretação do Poder Judiciário a partir da principiologia e ponderação.

A tese que este artigo pretendeu provar é que referências dessa natureza à teologia no direito revelam não só um injustificado preconceito, que ignora ou diminui as particularidades deste campo ainda superficialmente explorado pela teoria jurídica, mas também revelam um visível desconhecimento dos paralelos existentes entre as experiências na teologia e no direito. Contudo, devem ser traçados com cautela os paralelos entre as experiências interpretativas no direito judaico, islâmico e norte-americano, uma vez que, como é particular das religiões, o direito no judaísmo e islamismo coloca-se a disciplinar não apenas um sistema sociopolítico, mas principalmente um sistema ético-religioso, ao contrário da religião civil estadunidense. Entretanto, os paralelos tornam-se possíveis na medida em que os três ordenamentos legais encontram seu fundamento em um texto jurídico escrito e vinculativo, que deve ser interpretado de maneira a funcionar como base legal de uma sociedade dinâmica. Em todos os casos, seja no judaísmo, no islamismo ou no constitucionalismo norte-

\footnotetext{
${ }^{22}$ Mulá é a denominação atribuída aos clérigos muçulmanos versados na teologia islâmica, principalmente em suas tradições - hadith - e em suas leis - fiqh. 
americano, o direito é interpretado e decidido, em última análise, por seres humanos.

A partir do momento em que a vida do homem em sociedade passou a ser ordenada juridicamente por mandamentos encerrados por escrito em um documento, apenas ao homem competiria interpretá-los, estejam eles previstos em documentos religiosos, a exemplo da Torá e do Corão, ou em documentos político-jurídicos, a exemplo da Constituição. A abordagem dos discursos jurídicos desenvolvidos no interior de cada um dos sistemas permite identificar semelhanças entre os métodos encontrados na busca por resposta à pergunta que é igualmente imposta às três ordens jurídicas: "Como podem os indivíduos fielmente interpretar e aplicar o texto sem indevidamente impor suas opiniões pessoais sobre o Direito?” (QURAISHI, 2006, p. 119). Nessa busca, recorreram os intérpretes e aplicadores do direito à tradição, à razão e ao literalismo, sob distintas denominações: saduceus, fariseus, hanbalis, zahiris, shafi'is, malikis, ghazalis, literalismo, Living Constitution e Original Intent. Parecem, portanto, bem delineadas as opções metodológicas disponíveis àqueles que estão comprometidos em interpretar o texto sem comprometer sua legitimidade legal, seja no direito ou na teologia.

\section{REFERÊNCIAS}

ALEINIKOFF, Thomas Alexander. Constitutional Law in the Age of Balancing. The Yale Law Journal, v. 96, n. 5, April 1987.

BARROSO, Luís Roberto. Neoconstitucionalismo e constitucionalização do Direito. (O triunfo tardio do Direito Constitucional no Brasil). Revista Eletrônica sobre a Reforma do Estado (RERE), Salvador, Instituto Brasileiro de Direito Público, n. 9, mar./abr./maio, 2007. Disponível em: <http://www.direitodoestado.com.br/rere.asp>. Acesso em: 4 ago. 2013.

BENVINDO, Juliano Zaiden. On the limits of constitutional adjudication: deconstructing balancing and judicial activism. Heidelberg: Springer, 2010.

BICKEL, Alexander. The least dangerous branch: the Supreme Court at the bar of politics. New Haven and London: Yale University Press, 1962.

CITTADINO, Gisele. Poder Judiciário, ativismo judiciário e democracia. Alceu, v. 5, n. 9, jul./dez. 2004.

DIMOULIS, Dimitri: Uma visão crítica do neoconstitucionalismo. In: LEITE, George Salomão; LEITE, Glauco Salomão (orgs). Constituição e efetividade constitucional. Salvador: JusPodium, 2008.

FARRAND, Max. The Records of the Federal Convention of 1787. New Haven: Yale University Press, 1937. 
FRANK, Nathaniel. Scalia the Mullah. Disponível em: <http://www.slate.com/articles/news_and_politics/jurisprudence/2013/06/scalia_and_gay_ma rriage_how_the_justice_misunderstands_morality.html>. Acesso em: 15 ago. 2013.

FRIEDMAN, Barry. The importance of being positive: the nature and function of judicial review. University of Cincinnati Law Review, v. 72, 2004.

GERHARDT, Michael J. A tale of two textualists: a critical comparison of Justices Black and Scalia. Boston University Law Review, v. 74, n. 25, 1994.

GOOLAM, Nazeem M. I. Ijtihad and its signification for Islamic legal interpretation. Michigan State Law Review, n. 6, 2006.

GREY, Thomas C. The Constitution as Scripture. Stanford Law Review, v. 37, n. 1, Nov., 1984.

HALLAQ, Wael B. Was the gate of ijtihad closed? International Journal of Middle East Studies, v. 16, n. 1, mar., 1984.

HAMILTON, Alexander; JAY, John; MADISON, James. The Federalist Papers. Raleigh, NC: Sweetwater Press, 2007.

HIRSCHL, Ran. Towards Juristocracy: The Origins and Consequences of the New Constitutionalism. Cambridge: Harvard University Press, 2004.

HO, Catherine. Scalia stands by his 'originalist' view on the Constitution. Disponível em: $<$ http://articles.washingtonpost.com/2012-01-22/business/35440010_1_originalism-abortionrights-shape-abortion-laws>. Acesso em: 15 ago. 2013.

HOLT, P. M.; LAMBTON, Ann K. S.; LEWIS, Bernard (ed.). The Cambridge History of Islam. Volume 2B. Cambridge: Cambridge University Press, 1970.

JACOBS, Louis. The Jewish religion: a companion. New York: Oxford University Press, 1995.

KAMALI, Mohammad Hashim. Principles of Islamic Jurisprudence. Islamic Texts Society: Cambridge, 1991.

LEVINE, Samuel J. Jewish Legal Theory and American Constitutional Theory: Some Comparisons and Contrasts. Hastings Constitutional Law Quarterly, v. 24, n. 2, 1997.

LEVINSON, Sanford. How Many Times Has the United States Constitution Been Amended? (A) < 26; (B) 26; (C) 27; (D) > 27. In: LEVINSON, Sanford (ed.). Responding to Imperfection: The Theory and Practice of Constitutional Amendment. Princeton: Princeton University Press, 1995a.

Introduction: Imperfection and Amendability. In: LEVINSON, Sanford (ed.). Responding to Imperfection: The Theory and Practice of Constitutional Amendment. Princeton: Princeton University Press, 1995b. 
LUTZ, Donald S. Toward a Theory of Constitutional Amendment. In: LEVINSON, Sanford (ed.). Responding to Imperfection: The Theory and Practice of Constitutional Amendment. Princeton: Princeton University Press, 1995.

MAUS, Ingeborg. O judiciário como superego da sociedade - o papel da atividade jurisprudencial na "sociedade órfã". Novos Estudos, São Paulo, n. 58, CEBRAP, 2000.

MELCHERT, Christopher. The formation of the Sunni schools of law, 9th-10th centuries $C$. E. Leiden; New York; Köln: Brill, 1997.

NEVES, Marcelo. Entre Hidra e Hércules: princípios e regras como diferença paradoxal do sistema jurídico. São Paulo: Editora WMF Martins Fontes, 2013.

PAIXÃO, Cristiano; BIGLIAZZI, Renato. Histórica constitucional inglesa e norteamericana: do surgimento à estabilização da forma constitucional. Brasília: Editora Universidade de Brasília/Finatec, 2011.

QURAISHI, Asifa. Interpreting the Qur'an and the Constitution: similarities in the use of text, tradition, and reason in Islamic and American jurisprudence. Cardozo Law Review, v. 28, n.1, oct., 2006.

SAEED, Abdullah. Interpreting the Qur'ān: Towards a contemporary approach. London and New York: Routledge, 2006.

SARMENTO, Daniel. O Neoconstitucionalismo no Brasil: Riscos e Possibilidades. In: NOVELINO, Marcelo (org.). Leituras complementares de Direito Constitucional: Teoria Da Constituição. Salvador: JusPodivm, 2009.

SCHIER, Paulo Ricardo. Novos Desafios da Filtragem Constitucional. Revista Eletrônica de Direito do Estado, Salvador, Instituto de Direito Público da Bahia, n. 4, out./nov./dez., 2005. Disponível em: <http://www.direitodoestado.com.br>. Acesso em: 4 de agosto de 2013.

STRACK, H. L.; STEMBERGER, Günter. Introduction to the Talmud and Midrash. Minneapolis: Fortress Press, 1996.

STRAUSS, David A. The living Constitution. New York: Oxford University Press, 2010.

SUPREME COURT OF THE UNITED STATES. Griswold v. Connecticut - 381 U.S. 479 (1965). Disponível em: <http://supreme.justia.com/cases/federal/us/381/479/> Acesso em: 3 maio 2014.

McCulloch v. Maryland - 17 U.S. 316 (1819). Disponível em: <https://supreme.justia.com/cases/federal/us/17/316/case.html> Acesso em: 3 maio 2014.

State of Missouri v. Holland - 252 U.S. 416 (1920). Disponível em: <https://supreme.justia.com/cases/federal/us/252/416/case.html> Acesso em: 3 maio 2014.

THE FOUNDERS' CONSTITUTION. v. 1. Editor: Julian P. Boyd et al. Chicago: The University of Chicago Press, 2000. Disponível em: <http://presspubs.uchicago.edu/founders/print_documents/v1ch2s23.html>. Acesso em: 3 maio 2014. 
TUSHNET, Mark. Alternative forms of judicial review. Michigan Law Review, v. 101, n. 8, 2003.

WHITE, James Boyd. When words lose their meaning: Constitutions and Reconstitutions of Language, Character and Community. Chicago: The University of Chicago Press, 1985.

WHITTINGTON, Keith E. Political Foundations of Judicial Supremacy. Princeton: Princeton University Press, 2007.

WOOD, Gordon S. The Creation of the American Republic, 1776-1787. Chapel Hill: University of North Carolina Press, 1969.

ZOHAR, Noam J. Midrash: Amendment through the Molding of Meaning. In: LEVINSON, Sanford (ed.). Responding to Imperfection: The Theory and Practice of Constitutional Amendment. Princeton: Princeton University Press, 1995.

\title{
THE INTERPRETER IN FRONT OF THE TEXT: APPROXIMATIONS BETWEEN THE READING OF THE TORAH, OF THE QUR'AN AND OF THE CONSTITUTION
}

\begin{abstract}
The Brazilian constitutional literature of the late twentieth century and early twenty-first century revealed a fascination for principles and for weighting. The weakening of the normative character of the Constitution was attributed to the legal-axiological discourse of Constitutional Courts, whose justices would practice a constitutional theology to deduct directly from the text all the correct values and behaviors. However, as it is in Law, there is a constant concern in theology about the methods of interpretation of sacred texts that makes impossible to reduce its rich hermeneutical experience to a jurisprudence of values. To illustrate the argument, we will explore the debate over the reading of the Torah and of the Koran, in order to show the different possible interpretive methods. Secondly, we will focus on American constitutional history, especially in regard to the relationship between interpretation and amendment and to the hermeneutical role of the Supreme Court, so that, in the conclusion, we can draw parallels between the interpretation of the Torah, of the Qur'an and of the Constitution.
\end{abstract}

KEYWORDS: Constitutional amendment. Constitutional interpretation. Qur'an. Torah.

Recebido em: 17 de dezembro de 2013

Aprovado em: 26 de maio de 2014 